\title{
Determinação do ponto de colheita na produção de alho
}

\author{
Carlos Manoel de Oliveira; Rovilson J. de Souza; José Hortêncio Mota; Jony Eishi Yuri; Geraldo M. de \\ Resende \\ UFLA, C. Postal 37, 37200-000 Lavras-MG; E-mail: jonyyuri@uol.com.br
}

\begin{abstract}
RESUMO
O ponto de colheita de cultivares de alho tropical foi obtido através de um experimento conduzido na UFLA (MG), no delineamento de blocos casualizados, em esquema fatorial $4 \times 5$, com quatro repetições, avaliando quatro cultivares (Gigante Curitibanos, Gravatá, Gigante Lavínia e Gigante Roxo) e cinco épocas de colheita (134, $141,148,155$ e 162 dias após o plantio). Avaliou-se a produtividade total de plantas, produtividade total de bulbos e características físico-químicas (teor de sólidos solúveis, acidez titulável e índice de $\mathrm{pH}$ ). Os resultados obtidos permitiram verificar que as épocas de colheita influenciaram significativamente a produção e as características físico-químicas. A máxima produtividade foi obtida aos 148 e 156 dias após plantio, períodos em que se observou também aumento nas concentrações de sólidos solúveis e ácidos orgânicos no suco do alho.
\end{abstract}

Palavras-chaves: Allium sativum L., épocas de colheita, produtividade, $\mathrm{pH}$,sólidos solúveis.

\begin{abstract}
Determination of the harvest date for garlic cultivars

The harvest point for tropical garlic cultivars was determined through an experiment carried out in the Universidade Federal de Lavras, Brazil, with randomized block design, in a 4 x 5 factorial scheme, four replications, testing four cultivars: Gigante Curitibanos, Gravatá, Gigante Lavínia and Gigante Roxo and five harvesting dates: 134, 141, 148, 155 and 162 days after planting. The total yield of plant, total yield of garlic bulbs and physical-chemical characteristics (soluble acids content, titrable acidity and $\mathrm{pH}$ indices) were determined. The harvest date influenced significantly the yield and physical-chemical characteristics: Maximum yield, soluble solids concentration, and organic acids in garlic juice were obtained when harvesting at 148 and 156 days after planting date.
\end{abstract}

Keywords: Allium sativum L., harvesting time, yield, $\mathrm{pH}$, soluble solids.

\section{(Recebido para publicação em 15 de maio de 2002 e aceito em 19 de maio de 2003)}

$\mathrm{O}$ Brasil é um dos países que mais consome alho no mundo, a maior parte comercializada no mercado in natura, ainda que o consumo de pastas e outros produtos processados de alho venha crescendo gradativamente. Nos grande centros o abastecimento até a década de 1970 era feito mediante alho importado, principalmente da Argentina e Espanha. Com a adoção das pesquisas e de tecnologias o alho nacional passou a competir em condições de igualdade (tipicação) com os alhos importados (Boeing \& Seben, 1995). Entre os fatores que contribuíam para essa importação era o fato da Argentina ser, país com boa logística, condições edafoclimáticas bem mais favoráveis que o Brasil, além de o custo de produção ser menor que o brasileiro. Para contornar essa situação, os produtores brasileiros abdicam da qualidade final, antecipando a colheita para fugir do período de safra e garantir preços satisfatórios para o alho produzido.

O ponto de colheita é fator importante em todo processo agrícola, sendo que a determinação do melhor período de colheita permite o máximo aprovei- tamento pós-colheita do produto vegetal por apresentar melhor qualidade e o mínimo de perdas. A qualidade pós-colheita relaciona-se ao conjunto de atributos ou propriedades que tornam produtos agrícolas apreciados como alimento. Esses atributos, por sua vez, dependem do mercado de destino, como comercialização após colheita, armazenamento, consumo in natura ou processamento (Chitarra, 1994). Muitas vezes a decisão da colheita ocorre em função do preço do produto, desconsiderando que características fisiológicas, como acumulação de matéria seca, são importantes na conservação posterior do produto. As maiores acumulações de matéria seca em plantas de alho podem significar bulbos fisiologicamente mais desenvolvidos e com menores teores de umidade, melhorando a sua capacidade de conservação (Saturnino, 1978; Chitarra \& Chitarra, 1990).

Uma das conseqüências mais graves da colheita do alho imaturo é o estouro de disco (rachamento simples em uma só fenda, ou duplo em cruz, do disco ou prato de inserção das raízes). Este de- feito é grave e merece especial consideração nas especificações de padronização, classificação e comercialização do alho (Saturnino, 1978).

Segundo Muller (1982) empiricamente, o ponto de colheita do alho baseia-se na senescência da parte aérea da planta e varia de cultivar para cultivar. Entretanto, faltam informações com base científica que possam confirmar a época ideal para a colheita e seu reflexo na conservação pós-colheita, sendo este o objetivo do trabalho.

\section{MATERIAL E MÉTODOS}

O experimento foi conduzido na UFLA (MG), a $918 \mathrm{~m}$ de altitude, latitude $21^{\circ} 14^{\prime} \mathrm{S}$ e longiitude $45^{\circ} 00^{\prime} \mathrm{W}$ GRW. O clima da região é do tipo Cwa com características de $\mathrm{Cwb}$, apresentando duas estações definidas: seca (abril a setembro) e chuvosa (outubro a março), segundo a classificação climática de Köppen. O experimento foi instalado em um solo classificado como Latossolo Roxo Distrofico, com as características químicas: $\mathrm{pH}$ em água: 5,7; matéria orgânica: 3,7\%; P: $23 \mathrm{mg} \mathrm{dm}^{-3}$; $\mathrm{k}: 171 \mathrm{mg}$ 
$\mathrm{dm}^{-3}$; Ca: 6,6 mmol $\mathrm{dm}^{-3} ; \mathrm{Mg}: 1,9$ $\mathrm{mmol}_{\mathrm{c}} \mathrm{dm}^{-3} ; \mathrm{V}: 67 \%$.

O plantio dos bulbos foi realizado em 15/04/98, utilizando o delineamento experimental em blocos casualizados com 4 repetições, em esquema fatorial $5 \times 4$, com cinco épocas de colheita (134, 141, 148, 155 e 162 dias após a semeadura), e quatro cultivares tropicais: Gigante Curitibanos, Gravatá, Gigante Lavínia e Gigante Roxo, totalizando 20 tratamentos. A primeira época de colheita, aos 134 dias, foi pré-estabelecida como o início das avaliações baseadas na prática corriqueira dos produtores da região de Ouro Fino, MG. Com esta idade, as plantas de alho ainda estão completamente verdes. A colheita prosseguiu a cada 7 dias até a última colheita, quando as plantas apresentavam ciclo de 162 dias e completamente secas. Cada parcela foi constituída de 40 plantas, distribuídas em 4 linhas de plantio e 10 plantas por linha, apresentando uma área útil e total de $1,50 \mathrm{~m}^{2}$ (1,0 $\mathrm{m}$ de comprimento x 1,5 m de largura).

A adubação de base foi feita seguindo critérios da Comissão de Fertilidade do Solo do Estado de Minas Gerais: 150 $\mathrm{kg} \mathrm{ha}^{-1}$ de $\mathrm{P}_{2} \mathrm{O}_{5} ; 40 \mathrm{~kg} \mathrm{ha}^{-1}$ de K2O; 15 $\mathrm{kg} \mathrm{ha}^{-1}$ de bórax e $10 \mathrm{~kg} \mathrm{ha}^{-1}$ de sulfato de zinco. Foram utilizados $80 \mathrm{~kg} \mathrm{ha}^{-1} \mathrm{de}$ $\mathrm{N}$ como fonte uréia sendo parcelados $1 / 3$ no plantio, $1 / 3$ aos 45 dias e $1 / 3$ aos 70 dias após o plantio. Os tratos culturais foram realizados de acordo com as necessidades da cultura e a irrigação por aspersão foi realizada de acordo com Filgueira (2000), mantendo sempre o solo próximo da capacidade de campo.

Colheu-se 20 plantas por parcela, de acordo com os tratamentos e estas foram pesadas com todas as partes da planta para avaliar a produção total de plantas. Para todas as colheitas, as plantas foram submetidas a uma pré-cura ao sol, por cinco dias. Posteriormente foram pesadas sem a parte aérea e raízes (toalete) para avaliar a produção total de bulbos.

Após as avaliações de campo, os bulbos foram enviados para o laboratório, com a finalidade de se realizar análises físico-químicas. Para tal, com o auxílio de um triturador, os bulbilhos debulhados e descascados foram moídos até chegarem a uma consistência

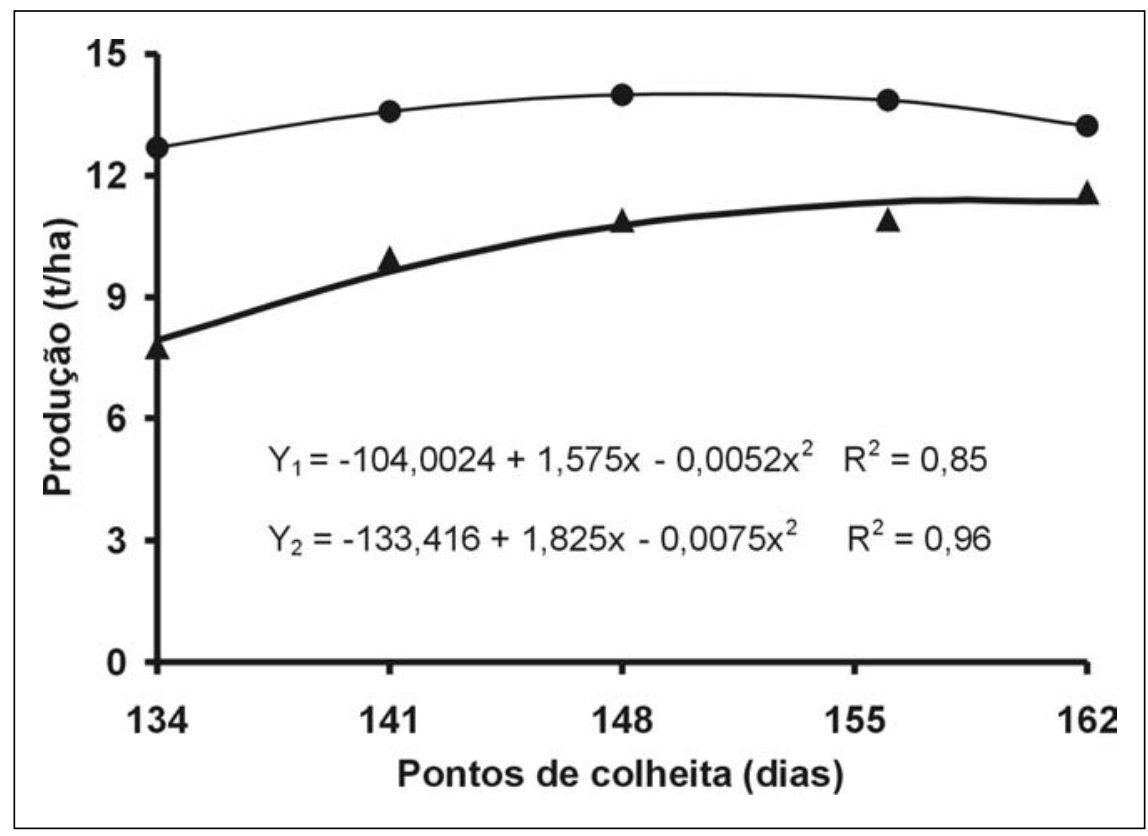

Figura 1. Produtividade total $\left(\mathrm{Y}_{1}\right)$ e produtividade total de bulbos $\left(\mathrm{Y}_{2}\right)$ em função dos pontos de colheita (dias após o plantio). Lavras, UFLA, 1999.

pastosa e homogênea. Este homogenato foi filtrado em gaze, retirando-se o suco para a realização das análises de sólidos solúveis, utilizando-se o refratômetro. Para a análise da acidez total titulável, o suco de alho foi titulado em uma solução de hidróxido de sódio 0,1 $\mathrm{N}$ e multiplicado pelo fator do ácido predominante no alho (ácido pirúvico), resultando em valores de acidez contidos em cada parcela analisada, segundo técnica preconizada pela AOAC (1970). Para a análise do $\mathrm{pH}$, mergulhou-se o eletrodo de um pHmetro.

\section{RESULTADOS E DISCUSSÃO}

Houve efeitos significativos independentes para cultivares e/ou épocas de colheita, não mostrando efeitos de interação entre estes fatores, variando com as características avaliadas.

A produção total de plantas aumentou à medida que a colheita foi efetuada com bulbos apresentando ciclos vegetativos maiores (Figura 1). Na primeira colheita, observou-se uma produtividade total de plantas média de 12,69 t ha ${ }^{-1}$ aumentando até chegar ao ponto de máxima produtividade $\left(14,00 \mathrm{tha}^{-1}\right)$, aos 148 dias após o plantio. A partir deste ponto observou-se uma queda de produção, verificada quando se colheu bulbos com ciclo vegetativo de 155 dias, sendo mais acentuado quando a colheita é feita aos 162 dias $\left(13,23 \mathrm{t} \mathrm{ha}^{-1}\right)$.

Entre as cultivares, pôde-se observar diferenças significativas em relação à produtividade total de plantas (Tabela 1). As cultivares que apresentaram os maiores valores para produção total de plantas foram Gigante Roxo, Gigante Lavínia e Gigante Curitibanos, com produções totais de plantas 14,41 $\mathrm{t} \mathrm{ha}^{-1}$, 14,20 t ha $^{-1}$ e 14,14 tha $^{-1}$, respectivamente. Somente a cultivar Gravatá diferiu estatisticamente das demais, com o menor valor em produção total de plantas $\left(11,13 \mathrm{t} \mathrm{ha}^{-1}\right)$. Entretanto, bem superior ao resultado obtido por Trindade (1985), que obteve produtividade da cultivar Gravatá em 4,50 t ha-1 e por Costa et al. (2001), que em experimento conduzido em Jaboticabal, SP, obteve com a cultivar Gigante Roxo, uma produtividade de $11,7 \mathrm{t} \mathrm{ha}^{-1}$.

Com relação à produtividade total de bulbos, por ocasião da colheita os alhos se apresentavam fisiologicamente verdes aos 134 dias após o plantio, com produtividade média de 7,92 $\mathrm{tha}^{-1}$ (Figura 1). Quando se colheu bulbos em um estádio mais avançado de maturação, respectivamente aos 155 e aos 162 dias após o plantio, a produtividade elevou-se consideravelmente, chegando ao máximo de $11,42 \mathrm{t} \mathrm{ha}^{-1}$, aos 156 dias após o plantio. A partir deste ponto, ob- 
Tabela 1. Produção total, produção total de bulbos, sólidos solúveis, acidez titulável e pH em função das cultivares de alho. Lavras, UFLA, 1999.

\begin{tabular}{lcccccc}
\hline Cultivar & $\begin{array}{c}\text { Produção } \\
\text { total (t ha-1) }\end{array}$ & $\begin{array}{c}\text { Produção } \\
\text { total bulbos } \\
\left(\mathbf{t ~ h a}^{-1}\right)\end{array}$ & $\begin{array}{c}\text { Produção } \\
\text { comercial de } \\
\text { bulbos } \\
\text { (t ha-1) }^{-1}\end{array}$ & $\begin{array}{c}\text { Sólidos } \\
\text { solúveis (\%) }\end{array}$ & $\begin{array}{c}\text { Acidez } \\
\text { titulável (\%) }\end{array}$ & PH \\
\hline Gig. Curitibanos & $14,14 \mathrm{a}$ & $11,19 \mathrm{a}$ & $10,55 \mathrm{a}$ & $33,98 \mathrm{ab}$ & 0,48 & 6,53 \\
Gravatá & $11,13 \mathrm{~b}$ & $7,57 \mathrm{~b}$ & $7,19 \mathrm{~b}$ & $33,20 \mathrm{ab}$ & 0,48 & 6,49 \\
Gig. Lavínia & $14,20 \mathrm{a}$ & $11,11 \mathrm{a}$ & $10,54 \mathrm{a}$ & $31,41 \mathrm{~b}$ & 0,47 & 6,45 \\
Gig. Roxo & $14,41 \mathrm{a}$ & $10,94 \mathrm{a}$ & $10,72 \mathrm{a}$ & $35,96 \mathrm{a}$ & 0,44 & 6,54 \\
\hline Média & 13,47 & 10,20 & 9,75 & 33,64 & 0,47 & 6,50 \\
\hline
\end{tabular}

Médias seguidas por letras iguais nas colunas não diferem entre si pelo teste de TUKEY a $5 \%$ de probabilidade.

Tabela 2. Equações de regressão para porcentagem de sólidos solúveis, acidez total titulável e pH em função dos pontos de colheita (dias após o plantio). Lavras, UFLA, 1999.

\begin{tabular}{lc}
\hline \multicolumn{1}{c}{ Características } & \multicolumn{1}{c}{ Equações de regressão } \\
\hline Sólidos solúveis (\%) & $Y=-17,191+0,343 x \quad R^{2}=0,91$ \\
Acidez total titúlavel (\%) & $Y=12,546-0,168 x+0,000584 x^{2} \quad R^{2}=0,97$ \\
$P H$ & $Y=9,348-0,0191 x \quad R^{2}=0,71$ \\
\hline
\end{tabular}

servou-se um decréscimo na produtividade, sendo a produção total de bulbos obtida na última colheita (aos 162 dias após o plantio), de 11,36 t ha-1. Deste modo, observa-se que em condições avançada de maturação, os resultados desse trabalho foram superiores aos apresentados por Konkel (1991) e Resende (1993), que obtiveram valores médios máximos de 8,7 e $9,5 \mathrm{t} \mathrm{ha}^{-1}$, respectivamente.

Um aspecto que pode induzir o produtor de alho a considerar vantajosa a colheita do alho verde, seria o fato do aumento da produtividade já que a parte aérea das plantas apresenta-se com alto teor de água, o que juntamente com o bulbo verde (produtividade total de plantas) daria esta interpretação errônea. Este fato pode ser observado ao se comparar à máxima produção total de plantas com a colheita sendo efetuada aos 148 dias com a máxima produção de bulbos, com o alho colhido aproximadamente aos 157 dias após o plantio.

Para a produtividade total de bulbos, observa-se que as cultivares Gigante Curitibanos, Gigante Lavínia e Gigante Roxo, com produções totais de bulbos de 11,$19 ; 11,11$ e 10,94 t ha $^{-1}$, respectivamente não diferiram estatisticamente, enquanto que a cultivar Gravatá diferiu e apresentou produção inferior
(7,57 t ha-1). Apesar da cultivar Gravatá apresentar a menor produção total de bulbos entre as cultivares testadas, a produtividade conseguida foi superior à média de produção em Minas Gerais, que é de 4,43 t ha-1 (Agrianual 1997).

A época de colheita interferiu de forma significativa no teor de sólidos solúveis. Verificou-se um aumento linear nos teores para a colheita de bulbos de alho em estádio mais avançado (Tabela 2). Observou-se menor concentração de sólidos solúveis para a colheita efetuada aos 134 dias após o plantio, com média de $28,83 \%$. O maior teor foi conseguido na última colheita (162 dias), quando os bulbos apresentavam características de maturação mais avançada, com média de $38,45 \%$. Este aumento no teor de sólidos solúveis à medida que a colheita foi atrasada mostra que pode haver uma relação entre os resultados apresentados para os teores de sólidos e a conservação pós-colheita. A cultivar Gigante Roxo foi a que apresentou maior teor de sólidos solúveis, com média de $35,96 \%$, sendo que o menor teor de sólidos solúveis foi verificado para a culPenoni (1993) observou em bulbos, em estádio avançado de maturação, porcentagem de sólidos solúveis da ordem de 30,38 e $32,75 \%$ para as cultivares Gitivar Gigante de Lavínia (31,41\%). gante Inconfidentes e Gigante Roxo, respectivamente. Já Mascarenhas (1978a, 1978b) encontrou valores para sólidos solúveis inferiores aos observados no presente trabalho, variando de $18,65 \%$ para a cultivar Caturra e 24,06\% para a cultivar Roxão, cultivadas em Sete Lagoas, MG.

Quanto à acidez total titulável e $\mathrm{pH}$, não se verificaram diferenças estatisticas entre as cultivares estudadas. Diferenças significativas para estas características foram observadas somente entre os pontos de colheita. A partir dos 134 dias, os teores de acidez total titulável se elevaram até a data da última colheita, aos 162 dias após o plantio (Tabela 2). Estes resultados foram semelhantes aos encontrados por Penoni (1993), que encontrou porcentagens de acidez titulável de $0,63 \%$ e $0,49 \%$ respectivamente, nas cultivares Gigante Inconfidentes e Gigante Roxo. No entanto, os resultados encontrados neste trabalho foram discordantes aos obtidos por Carvalho (1991) que, avaliando o tempo de armazenamento e qualidade de alho com a cultivar Amarante, relatou teores de acidez titulável de 1,08\% logo após a colheita. Para os valores de $\mathrm{pH}$ em função dos pontos de colheita, observou-se uma tendência linear decrescente na medida em que se prorrogou o ponto de colheita (Tabela 2). Os resultados foram semelhantes aos descritos por Chitarra \& Chitarra (1990), que verificaram uma relação inversa entre o $\mathrm{pH}$ e a acidez titulável total ( $\mathrm{pH}$ reduz à medida que aumentam os teores de acidez titulável total).

Em função dos resultados obtidos, nas condições em que se realizou o experimento, conclui-se que as cultivares 
Gigante Curitibanos e Gigante Roxo foram as de maior produtividade de bulbos; o ponto ideal para a colheita do alho situa-se a partir da maturidade do bulbo e varia de acordo com a cultivar, estando entre 148 a 156 dias após o plantio, para as cultivares avaliadas; e que a colheita do alho verde não reflete em ganho de produtividade, além de afetar as características de qualidade e apresentar menor teor de sólidos solúveis.

\section{LITERATURA CITADA}

ASSOCIATION OF OFFICIAL
AGRICULTURALCHEMISTS. Official methods of analysis. 11 ed. Washington, 1970. 1015 p.

AGRIANUAL. Anuário Estatístico da Agricultura Brasileira. São Paulo: FNP - Consultoria e comércio, 1997.

CARVALHO, V.D. Tempo de armazenamento na qualidade do alho, $\mathrm{Cv}$ Amarante. Pesquisa Agropecuária Brasileira, Brasília, v. 26, n. 10, p. 1679-1684, 1991.

CHITARRA, M.I.F.; CHITARRA, A.B. Pós-colheita de frutos e hortaliças, fisiologia e manuseio. Lavras: ESAL/FAEPE, 1990. 293 p.
CHITARRA, M.I.F. Colheita e qualidade pós colheita de frutos. Informe Agropecuário, Belo Horizonte, v. 17, n. 179, p. 8-18, 1994.

COSTA, C.C.; CECÍLIO FILHO, A.B.; COELHO, R.L.; MAY, A.; SANTOS, G.M. Desempenho produtivo de cultivares de alho em Jaboticabal-SP. Horticultura Brasileira, Brasília, v. 19, suplemento CD-ROM, 2001.

FILGUEIRA, F.A.R. Novo manual de olericultura: agrotecnologia moderna na produção e comercialização de hortaliças. Viçosa: UFV, 2000. 402 p.

BOEING, G.; SEBEN, J.C. Alho.Instituto de planejamento e economia agrícola de Santa Catarina. Florianópolis, 1995. $114 \mathrm{p}$.

KONKEL, S. Efeito do vinhoto e do cloreto de potássio sobre algumas características morfológicas, fisiológicas e rendimento do alho (Allium sativum L.). 1991.63 p. (Tese mestrado), UFLA.

MASCARENHAS, M.H.T. Características de 17 cultivares de alho (Allium sativum L.) visando a possibilidade de desidratação do produto. II. Janaúba, MG. In: EPAMIG (Belo Horizonte, MG). Projeto olericultura, 76/77. Belo Horizonte, 1978 b. p. 33-34.

MASCARENHAS, M.H.T. Características de 13 cultivares de alho (Allium sativum L.) visando a possibilidade de desidratação do produto. I. Sete Lagoas, MG. In: EPAMIG (Belo Horizonte, MG). Projeto olericultura, 76/77. Belo Horizonte, 1978a. p. 31-33.
MÜLLER, J.J.V. Aspectos relacionados com a conservação de alho (Allium sativum L.). In: MÜLLER, J.J.V.; CASALI, V.W.D. (eds.). Seminários de olericultura. Viçosa: UFV, v. 3. p. 6395, 1982.

PENONI, A.S. Modificações na composição química e atividade antibacteriana de duas cultivares de alho (Allium sativum L.) durante armazenamento pós-colheita em condições ambientais. 1993. 75 p. (Tese mestrado), UFLA. RAGHEB, M.S.; ATWA, A.A.; HAMOUDA, M.A. Seasonal changes in garlic and its effects on bulbs during storage. Agricultural Research Rewiew, p. 157-165, 1972.

RESENDE, F.V.Comportamento em condições de campo de plantas de alho (Allium sativum L.) obtidos por cultura de meristema. 1993. 63 p. (Tese mestrado), UFLA.

SATURNINO, M.H.T. Colheita, cura, preparo embalagem, comercialização e armazenamento do alho. Informe Agropecuário, Belo Horizonte, v. 4, n. 48, p. 51-61, 1978.

TRINDADE, M.B. Efeito do armazenamento de bulbilhos após frigorificação sobre o desenvolvimento e produção de bulbos de alho (Allium sativum L.) Cultivar Chonan. 1985. 63 p. (Tese mestrado), UFLA. 